\title{
An Analysis of the Economic Basis and Effect of the Implementation the Two-Child Policy
}

\author{
Qiong Han, Ph.D. \\ School of Economics \\ Central University of Finance and Economics, Beijing, China. \\ Lecturer, International Business School \\ Yunnan College of Business Management
}

\begin{abstract}
Nowadays, the two-child has become a hot topic. Whether it is the national macro-policy formulation or the people's daily life decision-making, they are unknowingly faced with difficult choices: only one good, or two good? Especially the family that is at the age of marriage and childbearing has to face the choice. From the perspective of the national macro overall consideration and the micro-family individuals, it seems that the conditions for reference and choice are very different. How to make choices becomes more and more difficult, and the problem of the two-child, has risen to a higher level. Some experts have called for China to enter the Lewis turning point and face serious labor shortages and aging problems. It is necessary to fully open the two-child policy, increase the birth rate, and inject new impetus into economic development. In this regard, this article has different views. It is cautious about the policy of opening a twochild and encouraging the role of the two-child in economic development. It is undeniable that economic development cannot be separated from the labor force. In terms of the current economic situation, China's economic development needs more high-quality and high-level innovative talents are not simply problems that can be solved by a large population. Subject to our current resources, it is difficult for us to achieve the same number and quality of population. More cases are less and more precise or more and general. Therefore, in population policy, we need to be conservative rather than aggressive. With the influence of the development of the network economy and AI, the labor force with traditional skills will gradually be replaced, facing unemployment and re-employment. In this case, the fertility rate will be increased according to past experience and estimation, and more low-skilled labor and will be added. The lack of creative labor force will have a negative impact on future development. This article focuses on the analysis of the specific theory of advocating the two-child policy, and analyzes the impact of the two-child policy from the theoretical level and practice to illustrate the viewpoint of this article.
\end{abstract}

Keywords: Two-Child Policy, Demographic Dividend, Population Dependency Ratio, Labor Productivity

In May 2015, the Fifth Plenary Session of the 18th National Congress of the Communist Party of China pointed out: Under the circumstance that the basic national policy of family planning continues to be adhered to, it is considered to gradually improve the development of the population and advocate a strategy of giving birth to two children. This move means that China has implemented the end of the one-child policy for more than 30 years. Through this policy, we found a very interesting phenomenon, that is, the first generation of only children, if they choose to have a twochild, then they is the first generation of the only child, but also the last generation of the only child.

I believe that many people will have more or less their own views on the one-child policy. In many cases, we have heard and seen many negative comments. Personally, we believe that any policy has advantages and disadvantages. We must treat this issue objectively. The family planning policy implemented in China has its specific historical reasons and is a difficult choice made during a specific period of economic development. I remember someone once said: History does not allow assumptions. For history, we should accept and courageously face it and look forward with a positive attitude. And this is also the issue that this article will focus on.

The implementation of the universal two-child policy means that the family planning policy implemented in China since 1978 has come to an end. In order to avoid the painful lessons we have experienced, we need to be more cautious and rational in the demonstration and implementation of the two-child policy to ensure that the final effect of the policy is consistent with our expectations.

The Chinese economy has experienced a rapid development and attracted the attention of the whole world. However, after the high-speed operation, it has inevitably ushered in the bottleneck of development. The reason is that we have found that the driving force for economic growth is insufficient. The performance in the demographic dividend has disappeared. The rapid economic development from 2000 to 2012 benefited from the huge advantage of the population. With the disappearance of the demographic dividend in 2014, our advantage has gradually disappeared, which has caused the stagnation of economic development. 
The population seems to be the most important reason for restricting economic development. Therefore, we will conduct an in-depth analysis of the population issue to explore the economic logic of the second-child policy we have formulated and its implementation effects.

\section{Demographic Dividend}

As mentioned above, we believe that the main reason for the slowdown in economic development is the disappearance of the demographic dividend. Therefore, increasing the population is our urgent priority, so it seems reasonable to let go of the two-child policy. However, is the actual situation like this? We need to explore it in more depth.

(1) What is the demographic dividend?

In a specific period of economic development, a country's labor force has a higher proportion of the total population. In the same period, the child rearing ratio and old-age support are relatively low, and the economic development has sufficient labor and abundant savings. We call this situation for the demographic dividend. The demographic dividend was first proposed in the relevant reports of the World Bank and the United Nations. These reports agreed that in the process of population development, due to the change in the age structure of the population, there will be an age structure of "Large Middle and Small at Both Ends". The lower population dependency ratio has led to an increase in savings, and sufficient labor resources have provided a strong impetus for economic development. This special population age structure is very beneficial to economic development.

The demographic dividend is mainly affected by two factors, one is the fertility rate and the other is the aging population. The proportion of China's labor force began to decline in 2010, and the dependency ratio began to rise in 2011, indicating that China's demographic dividend is gradually disappearing. There are two main reasons for the low fertility rate. One is the decline in the birth rate caused by the "family planning" policy. And another is more and more imaginations of late marriage and late childbearing, which are very unfavorable for the development of the population.

The aging of China's population is mainly due to the age of the "baby boomers" in the early days of the founding of New China. In addition, it is also constrained by the increase in the number of elderly people and the increase in average life expectancy. Through the breakdown of the demographic dividend, we can easily find that there are two factors that affect the demographic dividend, fertility rate and aging. Fertility rate is affected by "family planning" and late marriage and late childbearing. There are three factors affecting aging: first, the first "baby boomer" population, second, the number of elderly people, and third, life expectancy. Therefore, whether the universal two-child policy can increase the demographic dividend requires us to explore and deserve our deep thought.

The demographic dividend is the population opportunity window brought about by the transformation of the age structure of the population during a certain period of time. It is not replicable. China's demographic dividend is formed during the special development stage of China's economic development. Putting aside the two-child policy, according to the data of the past two years, the proportion of the two-child is not as high as expected. Even if the number of births expected by the experts is reached, there is still no way to offset the vacancy of the labor force. The effect is worth exploring.

(2) Population dependency ratio

The population dependency ratio is the ratio of children aged 0-14 years and those aged 65 and over to the workforce (usually 15-64 years old) in the total population. The greater the ratio, the more people need to be raised by a single workforce. It means that the overall burden of society is heavier. The dependency ratio can be divided into the child dependency ratio and the old-age dependency ratio according to the different age groups.

At present, the population dependency ratio in China is the same: from 1949 to 2012, the proportion of children changed from the rising trend in 1949 to the downward trend in 2012. In the same period, the proportion of the labor force first declined, and then began to rise. It has started to decline in two years; the proportion of the elderly aged 65 and over has remained basically between $3.5 \%$ and $5.5 \%$ before the 1980s. It has shown an upward trend since 1990, and the old-age dependency ratio is $7 \%$ in 2000 . This figure means that China has entered an aging society. At the end of 2012, this proportion has climbed to $9.4 \%$. With the change in the population dependency ratio, the age structure of our population has also undergone tremendous changes. From 1982 to 2010, the total dependency ratio showed a downward trend overall, from $62.6 \%$ to $34.2 \%$. In the subsequent 2011 and 2012, there was a continuous increase, with a total dependency ratio of $34.4 \%$ and $34.9 \%$, respectively, indicating that the population support burden of the whole society is increasing. Subdividing the dependency ratio shows that from 1982 to 2012, the dependency ratio of children decreased from $54.6 \%$ to $22.2 \%$, a large decline. At the same time, the old-age dependency ratio rose from $8.0 \%$ to 12.7\%. The population dependency ratio is expected to be $45.4 \%$ in 2030 and $59.1 \%$ in 2050 . 
The "China's Old Age Industry Development Report" published in 2014 mentioned that China has begun to enter an aging society. Although it is only an early stage, we must not lose sight of the danger of further development caused by the aging problem. At present, the industry generally believes that China's aging problem has its own characteristics, its main performance is: large scale, faster growth rate, showing the trend of not getting rich first.

Table 1: Changes in China's aging population

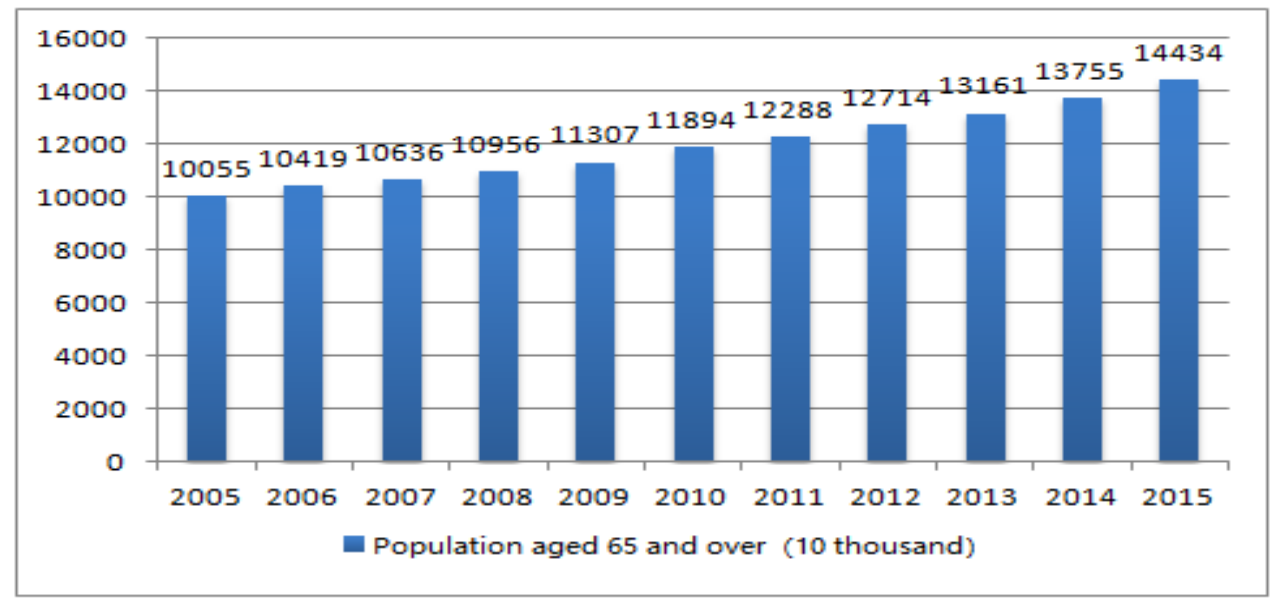

Table 2: Changes in China's Children's Population

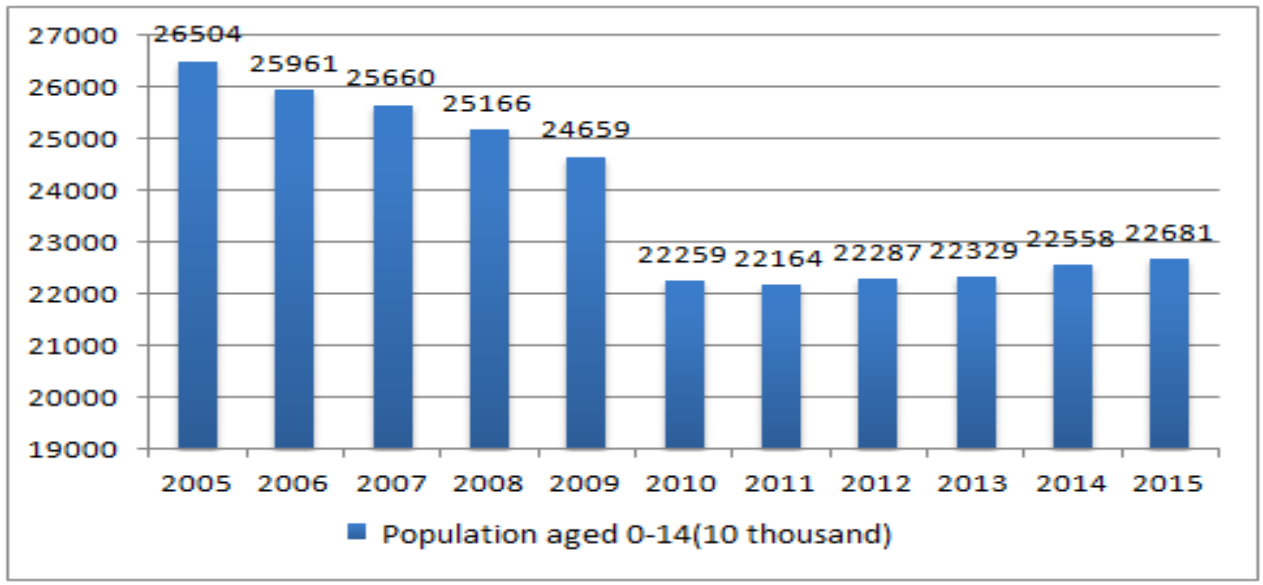

The total dependency ratio in China was $37 \%$ in 2015, with the old-age dependency ratio being $14.3 \%$ and the child dependency ratio being 22.6\%. The Chinese child-rearing ratio showed a downward trend from 2005 to 2015 , while the old-age dependency ratio during this period showed an increase.

Table 3: China's dependency ratio

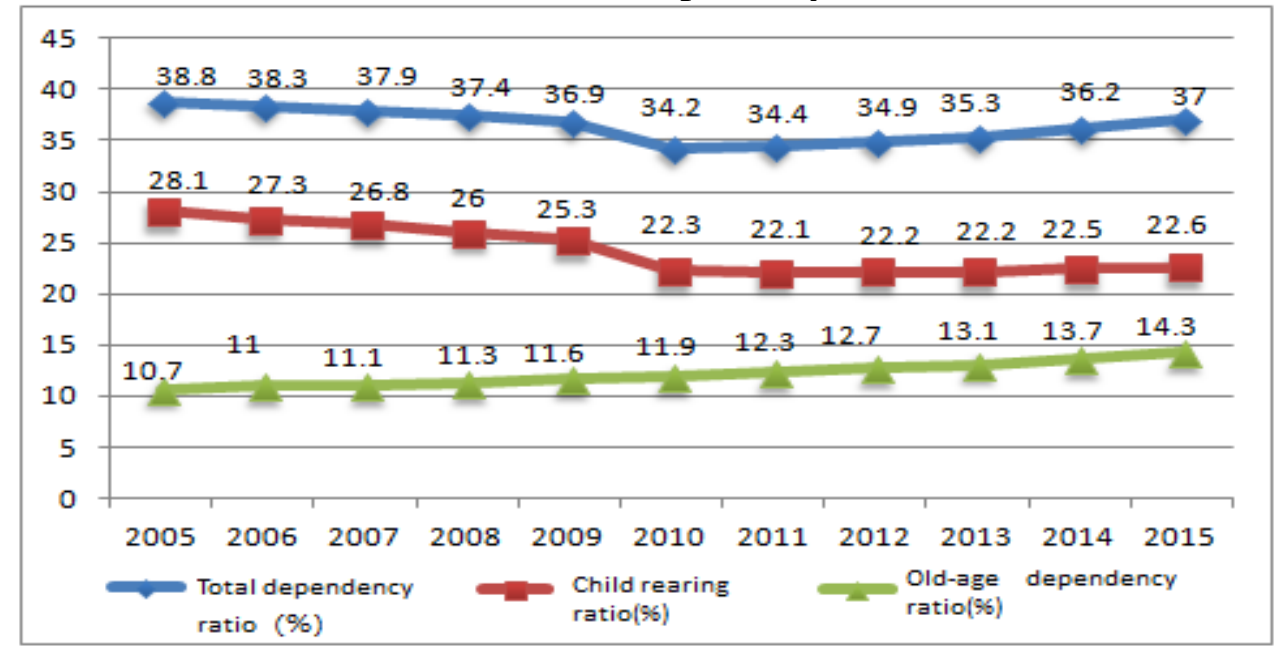


Through the above data comparison, it is not difficult to see that under the current population dependency ratio, the universal two-child policy will increase the support burden of the labor force and increase the overall dependency ratio of the society. It will not play a positive role in the promotion of the demographic dividend for the foreseeable period of time, but reduces the demographic dividend. China's aging population is very large, mainly because China's population base is too large. According to relevant data, the total aging population in the world will exceed 2 billion in 2050. Among them, China's aging population is very large, and its proportion is close to $25 \%$ of the global aging population.

China's aging population is on the rise. It is expected to approach 250 million by 2020 , increasing China's aging rate to $17.17 \%$. In China's elderly population, over 80 years old will rise to 30.67 million, the time for China to enter the super-aged country is around 2025. Since the implementation of family planning in China in 1980, a couple was asked to have only one child, and the population was strictly controlled. Therefore, the degree of aging in China is estimated to gradually reach the highest point estimated to occur in 2040. Then, China's aging level will show a gradual slowdown.

Table 4: China's population (over 60 years old)

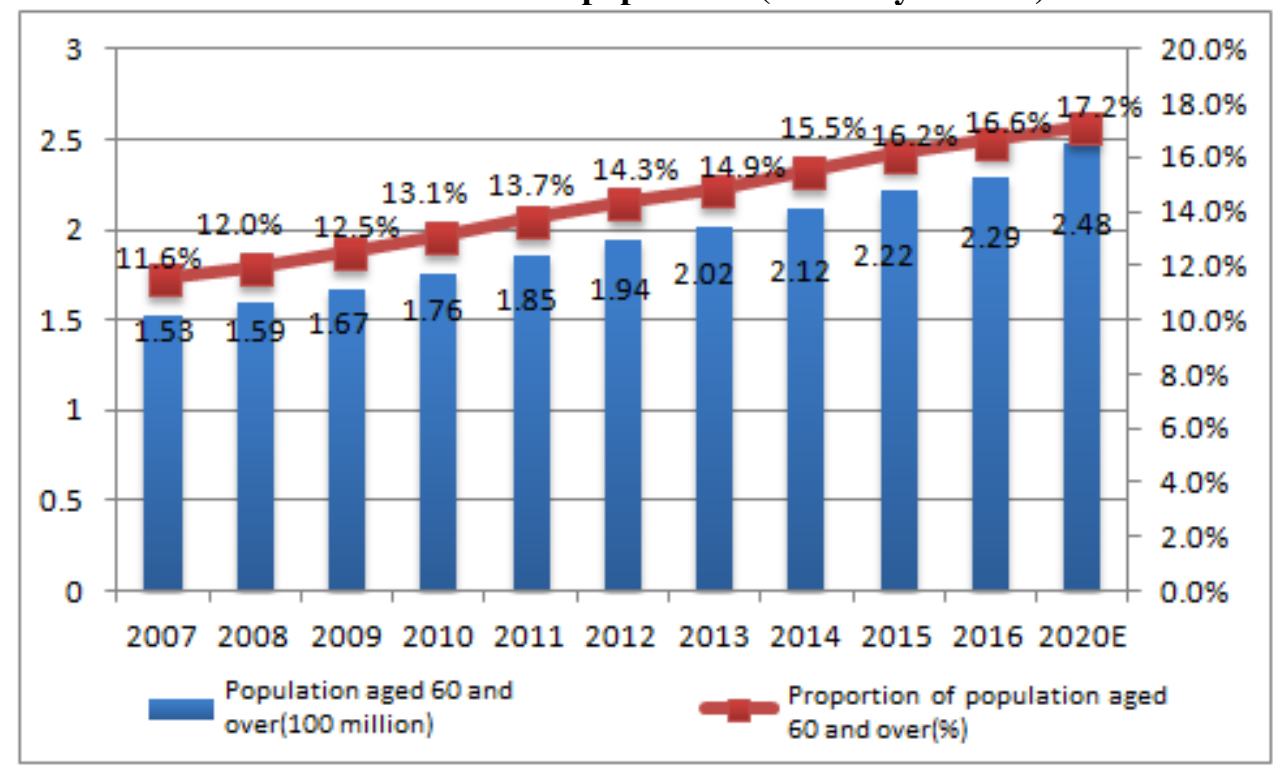

Has China's demographic dividend disappeared?

At present, the academic community has a more consistent consensus on the dependency ratio and the "demographic dividend period". The adoption ratio is no more than $50 \%$ as a criterion to measure whether a country enters the "demographic dividend period". Some domestic scholars have also expressed different opinions on this. For example, Chen Youhua, a professor at Nanjing University, used the Swedish life table of 1957 to measure that the dependency ratio of the "demographic dividend period" does not exceed 53\%. If it exceeds 59\%, it is considered to be Population debt.

The world's population dependency ratio continues to rise. Relevant data show that the proportion of developed countries is $48 \%$ by 2010 , with the old-age dependency ratio being $23.6 \%$ and the child-raising ratio being $24.4 \%$. As the aging of developed countries accelerates, the total dependency ratio of the society continues to increase. This ratio has changed to $73.4 \%$ in 2050 , the old-age dependency ratio is $44.6 \%$, and the child dependency ratio is $28.8 \%$.

The total population dependency ratio in underdeveloped countries and regions (excluding China) was 59\% in 2011, with the old-age dependency ratio accounting for $13.4 \%$ and the children accounting for $86.6 \%$. As the age structure of the population changes, the total dependency ratio will gradually decline. By 2050 , the total dependency ratio will fall to $54.2 \%$, and the old-age dependency ratio and the child-rearing ratio will be $18.8 \%$ and $35 \%$, respectively.

Changes in the total dependency ratio of the population in the least developed regions are also evident. The data show that the total dependency ratio in these regions was as high as $77.1 \%$. This high dependency ratio is mainly due to the contribution of the child-rearing ratio. The old-age dependency ratio was only $6 \%$. It is estimated that by 2050 , the total dependency ratio in these least developed regions will fall to 56.9, with the old-age dependency ratio rising to $26.1 \%$ and the child-rearing ratio falling to $33.8 \%$. 
WORLD POPULATION DEPENDENCY RATIO

unit : \%

\begin{tabular}{|l|c|c|c|c|c|c|c|}
\hline \multicolumn{1}{|c|}{ YEARS } & 1950 & 1960 & 1970 & 1980 & 1990 & 2000 & 2010 \\
\hline Developed Regions & 54.4 & 57.9 & 56.0 & 51.9 & 49.5 & 48.4 & 48.0 \\
\hline Less-Developed Region 5 & 74.8 & 81.8 & 85.8 & 81.3 & 75.9 & 67.3 & 59.0 \\
\hline Least Developed Region & 80.7 & 85.0 & 89.3 & 91.8 & 90.8 & 85.5 & 77.1 \\
\hline China & 63.2 & 77.3 & 77.3 & 68.5 & 51.4 & 48.1 & 38.2 \\
\hline \hline YEARS & 2015 & 2020 & 2025 & 2030 & 2040 & 2045 & 2050 \\
\hline Developed Regions & 51.8 & 55.8 & 59.5 & 63.0 & 68.2 & 70.7 & 73.4 \\
\hline Less-Developed Region & 56.5 & 55.0 & 53.8 & 52.9 & 52.4 & 53.0 & 54.2 \\
\hline Least Developed Region & 72.8 & 69.1 & 66.2 & 63.5 & 58.9 & 57.6 & 56.9 \\
\hline China & 37.7 & 40.7 & 41.9 & 45.4 & 56.8 & 58.5 & 59.1 \\
\hline
\end{tabular}

SOURCE: UN DESA (2011). World Population Prospects; The 2010 Revision.

China's highest dependency ratio appeared in 1960, about 80\%, and has been falling since then, and fell to $34 \%$ in 2010. The change in the old-age dependency ratio was relatively stable, and it remained at around 8\% from 1960-1990. The main factor affecting the change in the total dependency ratio is the change in the dependency ratio of children. Since 1990, the trend of old-age dependency ratio and child-rearing ratio has reversed, and the old-age dependency ratio has started to increase slowly, while the child-rearing ratio has decreased significantly. In 2012, the total dependency ratio ushered in a historical turning point, down to $32 \%$, and the increase in the old-age dependency ratio led to an increase in the total dependency ratio.

As the fertility rate gradually stabilizes, after 2015, the Chinese child-rearing ratio has changed little, and the old-age dependency ratio has become the main force driving the increase in the total dependency ratio. The problem of aging has become more and more serious, which has led to an increase in the old-age dependency ratio in China, which has led to a general increase in the total dependency ratio. It is expected that China's total dependency ratio will reach $50 \%$ around 2035.

\section{The Population Turning Point and Lewis Turning Point}

In fact, many of the literature's views are inconsistent with regard to the definition of inflection points. Some literatures use the inflection point of total population growth as an inflection point, while others use the inflection point of demographic change as an inflection point. In this article, we mainly discuss the inflection point of population change caused by demographic transition. The inflection point of the decline in the proportion of the working-age population is defined as the horizontal inflection point, that is, $\mathrm{gD}<0$; the inflection point that slows the growth rate of the workingage population is defined as the first-order inflection point, that is, $\operatorname{dgD} / \mathrm{dt}<0$, where $\mathrm{gD}>0$.

In his earliest article, Lewis defined the turning point of labor from infinite supply to scarcity as the Lewis inflection point. According to the above definition, it can be seen that the earliest Lewis inflection point is the horizontal inflection point. It appears as a turning point from the horizontal segment to the rising segment on the labor supply curve. The easiest way to identify Lewis's turning point is to observe whether the wage level has gradually increased from maintaining the basic living conditions of the labor force. Later, the Lewis inflection point was further subdivided. The model of Ranis and Fei divided the Lewis inflection point into two inflection points. The first inflection point was consistent with the definition of the inflection point originally proposed by Lewis, that is, the shortage of labor from infinite supply to the beginning of supply shortage. The second inflection point is called the commercialization point, that is, Lewis' second inflection point. After this inflection point, the labor supply growth rate increases. The most obvious performance is that the wages that maintain the basic survival of the labor force begin to increase rapidly (Figure). 


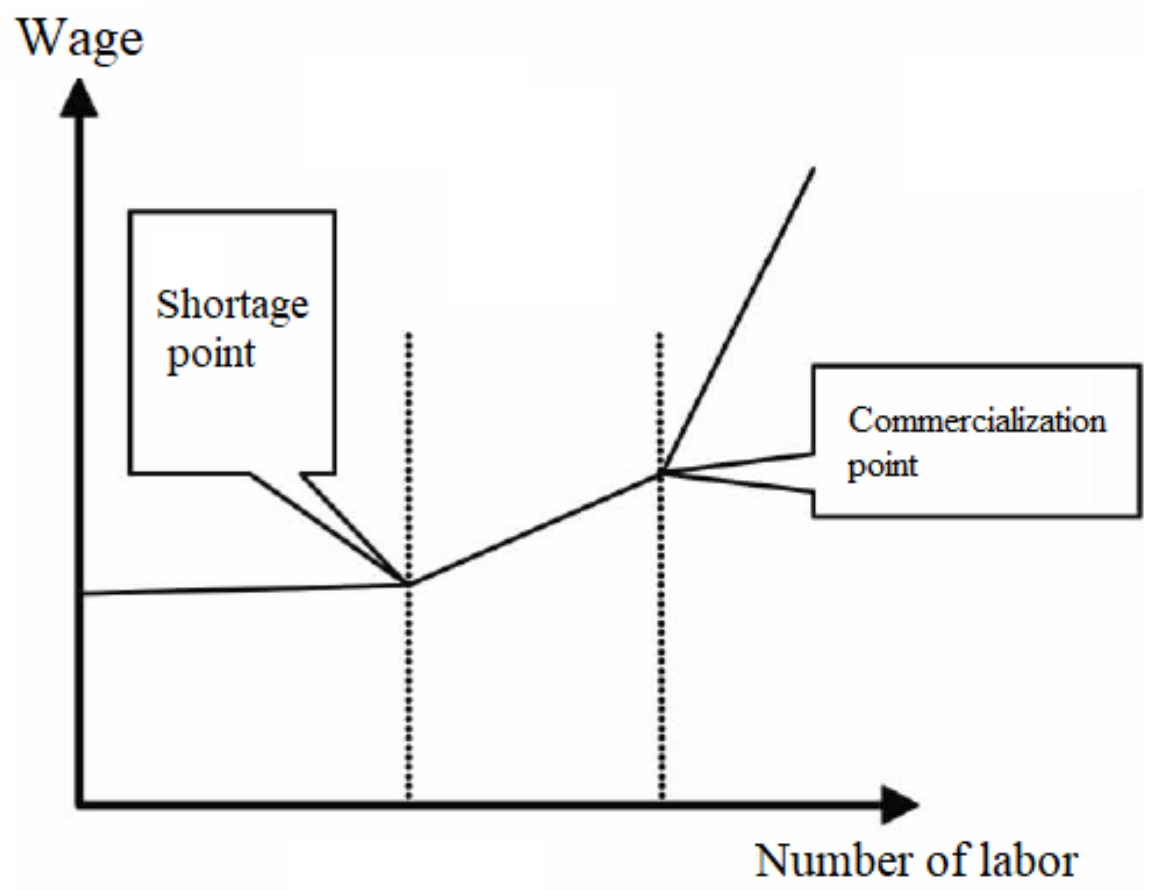

Lewis inflection point diagram

According to China's current development situation, although we are facing the dilemma of the decline in the labor force, this does not explain the arrival of Lewis' second inflection point. Looking back at the changing trend of China's economic growth, there are two main driving forces: one is the labor supply effect brought about by the demographic transition, and the other is the capital deepening effect caused by the increase in savings. Yin Jianfeng pointed out in the article "Population Turning Point, Lewis Turning Point and Savings/Investing Turning Point - Discussion on China's Economic Prospects" that the effect of the population turning point corresponding to the aging on the negative impact on economic growth depends on many specific factors. After Lewis' second inflection point, if the population turning point and the investment savings inflection point occur at the same time, it will bring about a decline in economic growth, and at the same time, it will reduce per capita output. The key to the current academic and social concerns is whether there will be a superposition of these three inflection points, which is fatal to the impact of economic growth.

In previous studies, although we have seen that China's labor inflection point (Lewis' first turning point) has arrived, the second turning point of China's Lewis has not yet come, as far as the savings-investment turning point, the population turning point and the Lewis inflection point meeting together are even more difficult to talk about. These circumstances all indicate that in the future China's economic growth, labor supply and capital deepening will play a huge role.

As mentioned above, Yin Jianfeng's model on the population turning point and economic prospects illustrated the relationship between the Lewis turning point and the population turning point. The population turning point does not necessarily lead to the Lewis turning point. The arrival of the Lewis turning point is not only related to the proportion of the working-age population, but also related to capital deepening and labor transfer.

In addition, Yin Jianfeng also pointed out in the inference 2 of the theoretical model of the article that the negative impact of the population turning point on the economy depends not only on the population turning point, but also on the relationship between capital and labor, that is, the impact of the increase in per capita capital can offset the impact of less labor force.

In view of the demographic factor, given that we have a large population base, we need to spend more time to digest the aging population of the first and second batch of baby boomers. Is it beneficial to implement the universal two-child policy at such a moment for economy development is still debatable? 


\section{The Improvement of Productivity}

National income is the sum of all labor products of a country's workers. Therefore, the change in population is closely related to economic and social development. Adam Smith said in the "The Wealth of Nations" that the amount of national income depends mainly on two factors, on the one hand, the proficiency of the workers, the skills and experience of the work, and on the other hand, the labor participation. That is, the ratio of those who participate in labor to those who do not participate in labor. Smith defined the first factor as "labor productivity," according to his conclusion: the level of national income of a country depends on the level of labor productivity in the country.

Smith said that there are obvious differences between civilized society and primitive society. In the primitive tribes, although everyone is engaged in labor, people are still undressed, unable to eat enough, sometimes to survive or even kill each other. In modern civilized society, although some people do not work, almost everyone can consume more materials than the primitive society. This is the result of the increase in total social output. As we have heard in our daily work, don't try to count the amount of cake you get, and you should try to make the cake bigger, so that the income will naturally increase. Therefore, according to Smith's point of view, improving labor productivity is the fundamental reason for increasing national income.

In fact, in our opinion, the logic of the causal relationship between fertility and economic development is problematic. Through the reality of economic operation for centuries, the fertility rate of human beings is subject to the market economy system. It is the highly developed market economy and the intensification of the globalization process, which has led to a general decline in fertility. A simple question, if we take the decline in fertility rate as the cause of the recession in the Japanese economic decade, how can we explain that China has strictly implemented the family planning policy in the past 30 years but the economy has developed at a high speed?

We cannot deny that the economy depends on the fact that human's develop, it is not the development of the "population", but by human productivity. In other words, productivity is undoubtedly the driving force for economic development. Here we have to make clear that the concept of population is completely different from the concept of productivity. There is a relatively complicated relationship between them. "The current productivity is the sum of the production capacity of individual producers" should be its original definition. In this case, if it is theoretically feasible to measure the production capacity of a single producer through quantitative evaluation, but in practice there is a great operational difficulty. How is productivity quantified? The productivity of a skilled worker and an apprentice must be different. What's the equivalence relationship between simple labor and complex labor? The enthusiasm and commitment of workers have become factors that constrain productivity, and these can be roughly summarized as labor capacity.

So we can generalize productivity into a simple formula: productivity = working-age population * labor capacity. The premise of this formula is that a single working-age population has the same working capacity, but this is not the case. In this formula, productivity is only an expectation of ability, and does not represent the ability to participate in real economic activities. Therefore, it is necessary to add the coefficient of "labor participation rate" to the formula. In addition, it is necessary to ignore the differences in the labor capacity of workers and the enthusiasm of work.

We further get "productivity = working-age population * labor participation rate * labor capacity". In this formula, we can see that "population" is not the only factor affecting productivity. The population is not equal to the number of people participating in labor, and the productivity depends on the population structure. The large number of labor does not mean labor efficiency. It is also closely related to the participation rate of workers. Voluntary unemployment and employment rate are important factors. However, specific to the individual worker, his ability to work is closely related to his or her education. The labor capacity has a vital impact, and education is a long-term, dynamic development process. The effect of education may not be so immediate, and its impact on productivity and economic development has a significant lag.

At present, the proportion of the elderly population in China is about $10 \%$, which is calculated according to the current birth rate (that is, assuming that the birth rate has not changed significantly), then by 2030, every two working people will have to raise one elderly person. By 2050 , the ratio of the working population to the elderly will reach $1: 1$, that is, one working population will have to raise one old man. According to the data, the United States has reduced the labor force by 5 million people in the past 22 years, while raising an additional 21 million. The most important reason is that the country has high labor productivity. The current per capita output value of the United States is 16.2, and China's per capita output value is only 2.3 , which is only $1 / 7$ of the United States. If China is now a working population needs to raise an old man, then in terms of labor productivity, China's labor productivity has increased to the level of the United States, which is seven times higher than that of the present, so that one working population can raise seven old man. In recent years, China's development direction on the goal of sustainable economic development has always been to change the mode of economic growth and increase labor productivity. 
In fact, as early as the 14th National Congress of the CPC, it was clearly stated that the market should play a fundamental role in resource allocation; the 18th National Congress has more clearly defined the importance of the market, and further pointed out that the market should play a decisive role in resource allocation. In the "13th FiveYear Plan", the way of economic development has been specified. China has clearly defined the focus of economic development in all aspects of policy. It can be said that China must fundamentally resolve the social crisis of the elderly, and its most effective way is to effectively improve labor productivity.

\section{$I V$. The Impact of the New Economy on the Traditional Economy}

\section{(1) Population growth status}

Many years ago, we have been worried about a problem, that is, China's population problem. According to the National Bureau of Statistics, China's population will exceed 1.5 billion. However, many years have passed, and China's population has not continued as fast as experts have predicted. Growth rate begins to slow down. This aspect may benefit from the family planning we have implemented since the 1970s. On the other hand, we have to admit that the development of the population is actually closely related to economic development. The progress of history tells us the fact that the more backward and underdeveloped, the more people are willing to have children, and with the development of society and the change of people's consciousness, the birth rate is gradually decreasing. For many reasons, there have been a lot of researches on this subject, so I won't go into details here. What we need to focus on is the relationship between our current population and economic development. Here we have to pay attention to a new force: the Internet economy. This is a factor that was not anticipated in the estimation process of our population experts and relevant statistical departments in the past. It is the emergence of the Internet economy that has brought about great changes in our lives. These changes include the number of traditionally employed people and the new requirements for their strengths and weaknesses.

(2) The impact of e-commerce development on employment

I believe that everyone has a very obvious feeling. In recent years, the real economy has been sluggish. To a large extent, we attribute the reason to the overall economic downturn, and we have neglected an indisputable fact that the development of e-commerce network operators is in full swing. Every year, Tmall"11.11", Tmall"12.12", JD "618", Suning"818", etc. If we count the operating performance of these e-commerce, compared with the previous real economy, the fact seems that the economic downturn is not enough can be drawn. It just shows that our way of life has changed quietly. In addition, there are a large number of overseas purchases and purchasing, our consumption power is still strong, but the methods are more diversified and the channels are more dispersed.

(3) The impact of consumption habits on traditional employment

The very important reason that can promote the development of these networks and e-commerce is that the new generation in our population structure has gradually become the main force of consumption after the 80s and 90s. They have mastered advanced technology and have a perspective and thinking that keeps pace with the times and globalization. The consumption power of the aging generation is declining. Due to the influence of ideas and thinking, after the 80s, 90s, and even 00s, they are more enthusiastic about the use of networks and emerging technologies. Therefore, our Tmall supermarket is gradually replacing the traditional retailers such as Wal-Mart and Carrefour, and the profits of offline stores are also gradually divided by the online platform, the business is bleak.

The jobs created by the real economy are gradually decreasing and disappearing. A large number of workers are facing unemployment and re-employment. Although the e-commerce platform also creates new jobs, the demand for personnel is generally declining compared with the real economy. This is also a question that must be considered in our future population and labor policies.

This has to be said to be a new trend facing human development and a challenge and progress towards the traditional economy. We must face up to the opportunities and challenges that arise in development, adapt to and respond to these changes with new thinking, and be able to remain invincible in development.

\section{The Development of Artificial Intelligence}

AI has gradually become a group that is more and more worthy of attention in people's lives. From the earliest American street, the robot is driving Uber at night, to the robot AlphaGO wars weiqi genius, and then to Baidu's CEO Li Yanhong to take the driverless car to participate in the 2017 AI Developer Conference. Even to the popular sex robots on the Internet, AI is almost beginning to enter all areas of our daily lives and work. The development of AI technology has begun to panic people, why panic? Because robots may replace humans in many fields in the future, as the author described in BeiJing Folding, more and more third-tier humans will be replaced by robots, And this part of the population has a larger proportion of the total population. 
Then we need to consider whether the future development will not change the population's needs. Or do we need so many people as we estimate now? How do we call the labor force to calculate and define? All of these issues need to be considered in the population policy. In formulating the two-child policy, it is not possible to cope with the temporary shortage of labor, and spend a lot of manpower and material resources to create another population problem that needs to be paid for several generations to gradually digest.

Throughout the history of the development of countries around the world, with the economic development, the birth rate declines and the total population tends to stabilize. It is an inevitable trend. We do not need to panic, nor need to overreact, we must face up to these problems. The aging that we are facing is also a global problem. We will learn from the advanced experience of the countries we have experienced and the smooth transition of our actual situation. According to the laws of economic operation and development, we will adjust through the market and eventually enter a benign development mechanism. If we excessively carry out policy interventions, the comprehensive second birth will inevitably bring about a new wave of birth climax, which will also cause a new round of aging peak, this will become a new obstacle to economic development.

\section{Summary}

In summary, regarding China's current population situation and the prospects for labor, our population policy, especially the two-child policy, requires a cautious attitude. The opening of policies, the orientation of public opinion, and the improvement of the social security system all require a clear attitude. For the two-child, we should maintain a neutral attitude as much as possible, discourage, not prohibit, and let the family and society make the most effective choice. China's economy is a relatively open market economy. We should give more initiative to the market and let the market adjust the supply and demand of the population and labor to promote the benign development of the economy.

\section{References}

Wang Ling. China's population negative growth inflection point disputes earliest 2021 at the latest 2030 [N].First Financial Daily, 2016-02-04 (A12).

Wang Qi. Lewis Turning Point, Demographic Dividend and China's Economic Growth Transformation [D].Southwest University for Nationalities, 2015.

The turning point of labor supply in China has decreased year by year [J]. Population and Family Planning, 2014, (01): 61. [2017-08-07].

Wang Weitong. Research on the "End Effect" of China's Demographic Dividend Economic Growth—Concurrently on the Chinese Economy after Lewis Turning Point [J].Finance \& Trade in Economics, 2012, (11): 14-20. [2017-08-07].

Fang Wei. Judgment of China Lewis' Inflection Point and New Population Problem[J].Chinese and Foreign Entrepreneurs, 2012, (17): 117-118. [2017-08-07].

Yin Jianfeng. Population Turning Point, Lewis Turning Point and Savings/Investing Turning Point_—Discussion on China's Economic Prospects [J]. Financial Review, 2012, 4(04): 1-17+122. [2017-08-07].

Hong Yong. The Vision, Demographic Bonus and Economic Growth of China's Lewis Turning Point[J].East China Economic Management, 2012, 26(08): 52-54+70. [2017-08-07].

Li Wei. "Labor shortage" reflects the current situation of demographic dividends - is China's Lewis turning point coming? [J].China Notary, 2012, (06): 31-33. [2017-08-07].

$\mathrm{Bu}$ Zhiming. On the Economic Transformation of the Lewis Turning Point at the End of China's Demographic Dividend Period [J]. China Engineering Consulting, 2011, (03): 28-34. [2017-08-07].

He Yang. The turning point of Chinese population__- Interview with demographer Yi Fuxian [J].Business Weekly, 2010, (14): 48-50. [2017-08-07].

Yusen, Wang Gaoshe, Yang Kejun. Discussion on the index of population dependency ratio in China [J].Journal of Shaanxi Administration Institute, 2008, (03):36-38. [2017-08-07]. DOI: 10.13411/j. Cnki.sxsx.2008.03.029

Sun Ziwei. Has China entered the "Lewis Turning Point"? - Concurrently on the economic growth demographic dividend [J].Economist, 2008, (01): 117-119. [2017-08-07]. DOI: 10.16158/j.cnki.51-1312/f.2008.01.010 